\title{
A Review of Domestic Internal Control Literature in Recent Years
}

\author{
Yixin Yuan \\ School of Management, Jinan University, Guangzhou, China \\ Email: 13250713649@163.com
}

How to cite this paper: Yuan, Y.X. (2019) A Review of Domestic Internal Control Literature in Recent Years. Modern Economy, 10, 1239-1252.

https://doi.org/10.4236/me.2019.104085

Received: March 29, 2019

Accepted: April 16, 2019

Published: April 19, 2019

Copyright (C 2019 by author(s) and Scientific Research Publishing Inc. This work is licensed under the Creative Commons Attribution International License (CC BY 4.0).

http://creativecommons.org/licenses/by/4.0/

\begin{abstract}
With the increasingly complex business environment, the construction of a scientific and effective internal control system has become an increasingly urgent requirement for enterprises. This paper demonstrates the research trends of domestic internal control topics in recent years through a brief exposition of the development process of internal control of enterprises and the combing of relevant internal control research literatures in recent years, so that readers can research the internal control of China in recent years. This paper can give readers a more comprehensive understanding about internal control.
\end{abstract}

\section{Keywords}

Internal Control, Literature Review

\section{Introduction}

Entering the 21st century, a series of financial scandals such as Ernst \& Young bankruptcy, global communications fraud, WorldCom fraud, Olympus financial fraud, Yinguangxia accounting account fraud, Sichuan Changhong huge amount of receivables, McCawlin disclosed false financial information, Wanfu Health Finance, Ziguang Guhan false profits and so on have gradually exposed the internal control ills of various listed companies in the securities trading market. The weak internal control and the opaque disclosure of internal control information have caused a series of financial problems in the current listed companies, which has caused them to fall into operational difficulties and caused many investors to face huge losses. With the exposure of internal control issues, the academic community has paid more and more attention to the study of internal control issues, and the attention of all sectors of society to the internal manage- 
ment of listed companies is also rising. There is also a growing body of literature on internal controls. After introducing the development process of internal control of enterprises, this paper reviews the internal control research literature of domestic mainstream journals from 2014 to 2016, and summarizes the research results of internal control in recent years, hoping to help readers to internalize in recent years. There is a more comprehensive understanding of the research dynamics of control.

This article is divided into four parts. The first part is the introduction. The second part describes the development of internal control. The third part summarizes the literature on internal control, which is described from five aspects: internal control effectiveness, internal control quality, internal control defects, internal control and risk prevention, and internal control of administrative institutions. The fourth part analyzes the research trends of internal control.

The theoretical contribution of this paper is to sort out the research results of domestic and foreign scholars on internal control in recent years, and on this basis, analyze the trend of internal control research, and lay a solid theoretical foundation for scholars who are interested in the direction of internal control research.

The documents selected in this paper are from authoritative journals at home and abroad. The literature is downloaded from China Knowledge Network Database, Wanfang Database and Google Scholar.

\section{The Development of Internal Control}

\subsection{Budding Period-Internal Containment}

The internal control theory in the modern sense was developed from the early internal containment. In the late eighteenth century, the first industrial revolution took place in the UK and the establishment of a factory system began. In the form of factory organization, in order to prevent confusion and errors in property management methods and records caused by the refinement of internal work, we began to establish a containment system for property and bookkeeping based on responsibility. By the middle of the $19^{\text {th }}$ century, American railway companies had organizational management innovations, and they had explored a simple internal control system including separation of duties, bookkeeping, and physical containment in terms of organizational structure, assignment of responsibilities, business procedures, and internal audit. The control of money, money, objects, etc., achieves the purpose of protection, guidance, and prevention. After entering the $20^{\text {th }}$ century, the focus of the audit has shifted from checking for errors and correcting the correctness and reliability of the balance sheet items. In practice, it has been found that: In the case of companies with internal containment systems, their errors and fraud are less, and the balance sheet The credibility is high; the audit results are good for all the businesses and links that implement internal containment. In this way, as long as the internal containment is checked whether it is established, sound and effective, the audit fo- 
cus can be planned. As a result, external audits began to strengthen internal corporate containment.

\subsection{Development Period-Internal Accounting Control and Internal Management Control}

In 1934, the US Securities Exchange Act first proposed the concept of "internal accounting control system". The Internal Control Special Committee of the Auditing Procedures Committee (CAP) made the following authoritative definition for internal control for the first time in 1949: "Internal control is designed to protect assets, ensure the reliability and accuracy of accounting data, and improve operational efficiency. Internal control is also designed to promote the implementation of the various policies formulated by the management. In October 1953, the Audit Procedures Committee (CAP) issued the Audit Procedures Announcement No. 19 (SAP No. 19), which divided internal control into accounting control and management control. In 1972, the American Auditing Standards Board (ASB) introduced a well-known definition of management control and accounting control in Announcement No. 1 (SAS No. 1): 1) Internal accounting control. Accounting controls consist of organizational plans and procedures and records related to the protection of assets and the reliability of financial information; 2) internal management controls. Management controls include, but are not limited to, organizational plans and procedures related to the decision process authorized by the management to handle economic operations and their records. This kind of authorization activity is the responsibility of the management department. It is directly related to the management department's execution of the organization's business objectives, and is the starting point for accounting control of economic business.

\subsection{Maturity—Management-Oriented Internal Control Framework}

In the 1980s, a new round of financial failures in the United States led to the bankruptcy of a large number of financial institutions. The survey found that almost all cases were related to the auditor's dereliction of duty. In 1992, the Coso Committee issued the "Internal Control-Integration Framework" report (referred to as the coso report), arguing that "internal control is implemented by the company's board of directors, management and other employees, and the efficiency of the operation and the reliability of financial reporting. The realization of the objectives of sexuality, compliance with relevant laws and regulations, etc. provides a process of reasonable assurance. From then on, internal control is no longer only regarded as a system and a mechanical regulation, but a dynamic management process and orderly Control System.

In 1996, coso released a report on "Internal Control Issues in the Use of Derivative Products", suggesting that models used to manage derivatives-related risks can be used to manage almost any type of risk. In 2001, Coso commissioned Puhua to develop a framework for corporate management to evaluate and improve enterprise risk management. During this period, Enron, WorldCom and other 
cases occurred, prompting the US Congress to enact the Sarbanes-Oxley Act (Sox Act) in 2002. The Act expands the requirement for public companies to maintain an internal control system, requiring management to verify and be certified by independent auditors. In 2004, based on the coso report and the sox bill, coso launched the Enterprise Risk Management-Overall Framework (the erm framework). Erm has basically completed the transformation of the role of internal control management features.

In 2013, coso developed a new version of the coso report based on the trend toward a more technologically advanced and globalized business environment, and stakeholders seeking a more transparent and accountable internal control system to support business decision-making and corporate governance. The new version retains the basic control of the internal control definition and the five elements, and further recognizes that internal control is the organization of a process consisting of uninterrupted tasks and activities, emphasizing "affected by the organization's board of directors, management and other personnel.". From the coso report (especially the new version of coso report) and erm analysis, we judge: First, internal control gradually returns to the endogenous nature of enterprise management needs; Second, internal control is regarded as a business management process, or a tool.

\section{Review of Internal Control Research}

Through the combing of internal control research at home and abroad in recent years, this paper finds that this year's research focuses on the following five aspects, namely internal control effectiveness, internal control quality, internal control defects, internal control and risk prevention, and administrative undertakings. Internal control of the unit, the following article will review the internal control research in chronological order from these five aspects.

\subsection{Effectiveness of Internal Controls}

The effectiveness of internal control refers to the degree to which the establishment and implementation of internal control provides reasonable assurance for the achievement of control objectives, including the effectiveness of internal control design and the effectiveness of internal control operations. Specifically, at the institutional design level. The effectiveness of internal control refers to the degree to which internal control objectives are achieved through the good fit and compliance between internal control elements and their external environment, and between system-related people and systems. At the operational level of the system. The effectiveness of internal control refers to the extent to which internal control objectives are achieved through the development and implementation of management activities such as power and responsibilities, risk control, supervisory incentives, and information communication.

Qi Dong, Wang Yunchen, and Fu Peng (2014) used a state-owned listed company as a sample to comprehensively discuss the mechanism of CEO incen- 
tives on the effectiveness of internal control. The study found that 1) giving CEO moderate over-reward incentives and equity incentives contributes to the effectiveness of internal control; 2) compared with the average CEO, CEOs with administrative experience will weaken the role of incentives in the effectiveness of internal control. The empirical evidence of the article indicates that CEO incentive is the key to improving the effectiveness of internal control at present, but the existing administrative appointment system of state-owned listed companies distorts the market-based incentive mechanism and weakens the effectiveness of internal control [1].

Zhao Yuanxian and Wu Weirong (2014) took the example of Shanghai stock market A-Share listed company from 2009 to 2012, and tried to establish a goal-oriented internal control effectiveness evaluation index system to empirically analyze the degree of marketization, legal system, government intervention, The impact of institutional factors such as CPA auditing and media attention on the effectiveness of internal controls. The results show that marketization, legal system, media attention and internal control effectiveness are significantly positively correlated; there is no significant correlation between CPA audit and internal control effectiveness; government intervention and internal control effectiveness are significantly negative Related. The conclusions of these studies indicate that the impact of institutional factors outside the firm must be considered when studying the effectiveness of internal control of firms [2].

Yu Haizong, Wu Yanling (2015) from the perspective of stock options and restricted stocks, taking a sample of listed companies in Shenzhen and Shanghai in 2009-2013 as a sample, discussing the implementation of equity incentives and the intensity of equity incentives during the contract period is effective for internal control. The study finds that the implementation of equity incentives can promote the improvement of the effectiveness of internal control; there is a positive u-type relationship between the intensity of equity incentives and the effectiveness of internal control, and this relationship is more significant under the restricted stock payment method, while in stock options There is no payment method; compared with state-owned listed companies, the implementation of equity incentives for non-state-owned listed companies can improve the quality of internal control, and there is a significant positive u-type relationship between equity incentive intensity and internal control effectiveness. It does not exist in listed companies. Research shows that equity incentives are one of the influencing factors of internal control quality, and its rational design can alleviate conflicts between principal and agent. Conversely, it may aggravate conflicts [3].

Lu Jingsheng, Zhao Yumei (2016) took the 854 panel data of listed companies in China from 2007 to 2013 as a sample, and analyzed the mechanism of the independence of the board of directors, the characteristics of the board of directors, the behavior of the board of directors, and the failure of internal control..Firstly, the characteristics of the board of directors (the size of the board of directors, the shareholding of the board of directors, the remuneration of directors and the completeness of the professional committee) and the behavior of the 
board of directors (the strength of the board of directors and the intensity of information disclosure of the board of directors), the failure of the board of directors and the internal control, and the passing of the characteristics of the board of directors are invalid. The research hypothesis of influence, and then construct the relevant theoretical model, and finally carry out empirical test and conclude that the characteristics of the board of directors have a mediating effect on the impact of internal control failure through the behavior of the board of directors, and it is a non-linear mediating effect [4].

\subsection{Internal Control Quality}

With the increasingly complex business environment, the construction of a scientific and effective internal control system has become an increasingly urgent requirement for enterprises. In this process, how to scientifically and reasonably evaluate internal control of enterprises is a key issue. To solve this problem, we first need to understand what factors are important to the quality of internal control. Therefore, the literature exploring the influencing factors of internal control is becoming more and more abundant, forming an important branch of the field of internal control research.

Chi Guohua, Yang Jin, and Zou Wei (2014) focused on the implicit soft factors affecting internal control. Starting from the background characteristics of executives, the 2009-2011 China A-share listed company was used as a research sample to empirically test the background of executives. The empirical test examines the influence of executive background characteristics on the quality of internal control. The research conclusions show that the background characteristics of senior executives have certain influence on the internal control quality of enterprises, and the background characteristics of different senior management have great influence on the internal control quality. The conclusions of this paper indicate that in the process of internal control implementation, we should pay attention to the role of soft factors, starting from the executives themselves and creating a good environment for internal control implementation, which has important implications for improving the internal control quality of enterprises. At the same time, this research helps to deepen the understanding of internal control from a higher level, providing a new perspective for related research [5].

Chen Hanwen and Zhou Zhongsheng (2014) used the internal control index of the internal control group of Xiamen University to examine the impact of internal control quality on corporate debt financing costs. The empirical results show that the better the internal control quality of the enterprise, the lower the financing cost of the bank debt obtained. Further research shows that compared with state-owned holding companies, the impact of internal control quality on corporate bank debt financing costs is more significant in non-state-owned holding companies; relative to financial market developed regions, corporate internal control quality on corporate bank debt financing costs The impact is more 
pronounced in areas with underdeveloped financial markets; the impact of internal control quality on corporate bank debt financing costs is more pronounced in industries with more competitive market competition. In addition, from the five first-level indicators of internal control, the first-level indicators affecting the bank's debt financing costs are mainly the company's internal environment and control activities [6].

Ji Dong, Fu Peng, Yang Dan (2015) divided the media into three categories: online media, policy-oriented media and market-oriented media. The system examined the impact of different types of media on the quality of internal control of listed companies with different property rights. The study found that 1 ) under the government-led internal control construction development model, network and policy-oriented media focus on improving the quality of internal control of listed companies, but market-oriented media attention cannot improve the quality of internal control of listed companies; 2) Network and policy Focusing media attention can mainly improve the internal control quality of central state-owned and private listed companies, but it cannot improve the internal control quality of local state-owned listed companies. This research is based on the realistic situation of China's transitional economy, which not only deepens the understanding of the function of media supervision and governance, but also provides a new perspective on how to more effectively supervise the internal control norms of listed companies from the outside [7].

Yin Meiqun, Zhao Gang, Zhang Jidong (2015) analyzed the data of the Shanghai Stock Exchange from 2011 to 2012, and concluded that the impact of changes in monetary policy on the quality of internal control of the enterprise, and found that the market micro-subjects will have a common reaction to macro-environmental changes., in turn, improve the ability of companies to respond to changes in monetary policy. After studying the Coso Committee's "Enterprise Risk Management Integration Framework" and our domestic control guidelines, the article has reasonably determined the variables that measure the quality of internal control and its influencing factors. Based on the empirical analysis of the data from 2011 to 2012, it is found that the tightness of monetary policy has a negative impact on the quality of internal control of the enterprise, and it has a reverse relationship with the quality of information disclosure of the company. In addition, the company with high information quality has macroscopic The response to monetary policy volatility is less than the response of companies with low information quality to macro-monetary policy volatility; due to the pressure of monetary policy, corporate governance will also promote the improvement of internal control quality [8].

\subsection{Internal Control Defects}

Internal control defects are classified into design defects and operational defects according to their causes, and are classified into major defects, important defects and general defects according to their influence degree. The literature on inter- 
nal control deficiencies is also very rich, mainly focusing on two angles. One is to study the problem of internal control defect disclosure, and the other is to study the influencing factors of internal control defects.

Wang Yilin, Wang Aiqun (2014), using the data of Shanghai Stock Exchange listed companies from 2011 to 2012, explored the relationship between internal control defect disclosure, internal control audit and debt cost. The study found that the disclosure of internal control defects by listed companies will significantly increase the cost of debt, but the internal control audit will not significantly reduce the cost of debt, and the internal control audit adjusts the relationship between internal control defect disclosure and debt cost: Only when the listed company does not disclose internal control defects, Internal control auditing will significantly reduce the company's debt costs. When listed companies disclose internal control deficiencies, internal control audits will increase the company's debt costs, but it is not significant. The conclusion of this study is to provide an empirical basis for the company and creditors to pay attention to the disclosure of internal control defects and internal control auditing, as well as the transformation of China's domestic information disclosure system from "voluntary" to "mandatory" [9].

Shao Chunyan, Wang Peifu, Zhou Yubo (2015) based on the data of China's manufacturing listed companies from 2009 to 2013, empirically tested the impact of ultimate controlling shareholders on internal control deficiencies. The research shows that the control rights and cash flow rights of the ultimate controlling shareholders are significantly negatively correlated with the internal control defects; the separation of the two powers of control rights and cash flow rights is positively correlated with internal control defects; the pyramid level is significantly positively correlated with internal control defects. The ultimate controlling shareholder is non-state and sometimes the separation of the two powers is positively related to the internal control defects but not significant. The ultimate controlling shareholder is sometimes the country, and the separation of the two powers is significantly positively correlated with the internal control defects. But the nature of the ultimate controlling shareholder does not result in large changes in the impact of control, cash flow and pyramid levels on internal control deficiencies. This suggests that improving the quality of internal controls requires consideration of the impact of the ultimate controlling shareholder [10].

Zhang Chao and Liu Xing (2015) studied the relationship between the information disclosure of internal control defects and the investment efficiency of corporate A-Share listed companies in China. Based on the empirical results of China's current internal control defect information disclosure, the listed company is in the disclosure

In the previous period, there was excessive investment behavior, and the tendency of over-investment in the latter period of the disclosure was weakened. For listed companies with weak audit supervision and low disclosure adequacy, internal control defect information disclosure was insufficient for over-investment 
and investment. Both have a significant impact. The above results are still valid after controlling the effects of self-selection bias. The research results show that although the reliability of internal control defect information of listed companies in China is still weak, the defect information disclosure behavior has a significant impact on the investment efficiency of specific enterprises [11].

Shang Zhaoyan, Qiu (2016) Using the data of the resignation of independent directors of China's A-Share listed companies in 2011-2013 shows that the voluntary resignation of independent directors is significantly and positively related to the major defects of the company's internal control, and the company whose independent directors resigned was received in the same year. The possibility of standard audit opinions will be significantly improved, which indicates that the voluntary resignation of independent directors does transmit a signal that the company's internal control is seriously flawed; further research finds that the strength of this signal will be significant due to the age of resigning independent directors. Differences, the initiative of the young independent directors to resign the behavior of the company's internal control major defects are more strongly signaled, the company will have a higher probability of receiving non-standard audit opinions [12].

\subsection{Internal Control and Risk Management}

Risk management is the core of internal control, and the ultimate goal of internal control is to control risk. Strengthening internal control and improving the company's risk management level have become an important starting point for a series of related policy regulations issued by domestic and foreign regulatory agencies.

Fang Hongxing and Chen Zuohua (2015) focus on the economic consequences of internal control from the perspective of dealing with corporate risks. The article deeply analyzes the mechanism of internal control to deal with corporate trait risks and systemic risks, and uses the motherboards of Shanghai and Shenzhen in 2009-2011. The A-Share listed company is a research sample and has conducted an empirical test on whether internal control can effectively deal with trait risks and system risks. Theoretical analysis and empirical results show that the higher the quality of internal control, the more effective it is to suppress the occurrence of specific factors, and the lower the level of trait risk. The higher the quality of internal control, the stronger the defense ability, and the ability to cope with economic factors or market factors. The stronger, the more effective it is to weaken the impact of external factors, which in turn leads to a significant reduction in systemic risk levels. This paper not only reveals the internal mechanism of internal control in the role of risk management, but also accumulates new empirical evidence for the implementation of internal control of listed companies and the implementation of relevant regulatory policies [13].

Ye Kangtao, Cao Feng, and Wang Huacheng (2015) explored the internal relationship between internal control information disclosure and stock price collapse risk. The study finds that with the improvement of the level of internal 
control information disclosure, the risk of stock price collapse will decrease significantly in the future; after controlling for endogenous issues, the conclusion is still established; in companies with high information asymmetry and poor profitability, the negative correlation is more significant. This study not only helps us to understand the influencing factors of the stock price collapse risk, but more importantly, it shows that the enterprise internal control information disclosure system introduced in recent years not only helps to prevent internal business risks, but also contributes to the health of China's capital market [14].

Xu Zhaohui, Zhou Zongfang (2016): Taking the 2009-2014 China Shenzhen-Shanghai A-share listed company as a sample, studying the impact of over-investment on the company's credit risk, and testing whether the improvement of internal control quality can effectively curb the credit risk caused by over-investment. And whether risk management of internal control differs in different nature of the company's property rights. The test results show that excessive investment behavior will significantly increase the company's credit risk, and the improvement of internal control quality level can effectively suppress the credit risk caused by over-investment, but the private nature of listed companies will weaken the risk control effect of internal control. It shows that under the impetus of the government, the internal control system of state-owned enterprises has achieved certain results, and the internal control of private enterprises needs to be further improved to reduce its development risks [15].

Wang Yonghai, Shi Qingmei (2016): This quasi-natural experiment was carried out by means of classification and batch implementation of the internal control specification system, using the trend-matching double difference and breakpoint regression empirical method to take the 2010-2014 Shanghai and Shenzhen board A-Share listed companies as The research sample empirically tests the risk tolerance effect of the implementation of the internal control specification system. The empirical research found that the implementation of China's internal control norm system not only did not inhibit, but increased the company's risk tolerance level. Further examine the impact of external institutional factors and corporate governance characteristics on the risk tolerance effect of the internal control norm system, and find that this risk is subject to incentive effects in companies with high marketization, as well as in high equity concentration and international "four". The "large" audited state-owned holding company is even more significant [16].

\subsection{Internal Control of Administrative Institutions}

In November 2012, the Ministry of Finance issued the "Regulations on Internal Control of Administrative Institutions" (Trial) (hereinafter referred to as "Unit Internal Control Regulations") nationwide, and held the implementation of internal control regulations for administrative institutions on July 19, 2013. The mobilization meeting required the national administrative institutions to be officially implemented from January 1,2014 . This is of great practical significance 
for China's public sector to respond to the worldwide economic crisis through the reform of administrative functions and the slowdown of China's economic growth. Following the release of the policy, since 2014, the literature on the internal control of administrative institutions has also been enriched.

Tang Dapeng (2014) is based on the objective reality of China's current fiscal austerity. The article combines the urgent situation of the promulgation and implementation of the Internal Control Regulations of Administrative Institutions (Trial) of the Ministry of Finance, and studies and discusses the internal control system of the international public sector, and with China. The national environment and political environment established by the internal control of the public sector are linked with the economic environment. From the perspective of institutional innovation, the theoretical basis and empirical support for the establishment of internal control in the public sector are analyzed, and the relevant research system of internal control is enriched [17].

Chen Yanli, Zhang Lina, Meng Yue (2014) through questionnaire survey, found out the weakness of the asset management of public institutions, and analyzed the reasons for the chaos of asset management in public institutions, combined with the direction of the state's management planning for institutions, designed a more scientific The feasible asset management model of the institution and its realization path have certain effects on improving the asset management of the institution [18].

Tang Dapeng, Ji Jinhai, Zhibo (2015) combined with the self-property of China's administrative institutions, based on the theoretical basis of internal control, moderately borrowed the relevant content of internal control evaluation of enterprise organizations, and selected the mode of internal control evaluation of administrative institutions. In-depth analysis and path discussion of important directions such as index construction have played a certain role in improving the unit governance structure and satisfying the external environment to strengthen the building of clean government and improve management level [19].

Tang Dapeng and Li Xinyao (2015) proposed the goal of improving the modernization of the national governance system and governance capacity at the Third Plenary Session of the 18th CPC Central Committee, requiring China's public sector to establish relevant theoretical frameworks and form a scientific and effective power restriction and coordination mechanism. Under the background of the Fourth Plenary Session of the 18th Central Committee, which emphasizes the concept of governing the country based on the system as the basis for governance, the research focus theoretically explores the internal relationship between the internal control of the state auditing and administrative institutions, and further demonstrates the internal control for the "new normal". Under the model, the checks and balances and constraints of the operation of China's government power, as well as the natural advantages of the state audit in promoting the establishment of the internal control of administrative institutions are unique advantages. The research believes that the national audit will become one of the main external driving factors for the internal control of power 
operation, and proposes specific improvements in the internal control system, such as organization optimization, business level process risk management and evaluation and supervision information disclosure [20].

\section{Future Research Prospects}

Through literature review, it has been found that in recent years, mainstream journals have rich literature on internal control research, and more focus on internal control effectiveness research, internal control quality research, internal control defect research, internal control and risk prevention. The article mostly uses empirical analysis methods to study various factors affecting internal control, focusing on equity incentives, corporate governance, and media governance. However, most of the existing articles have not been further classified by industry after conducting research on the Shanghai and Shenzhen A-Share listed companies. The quality of internal control in different industries, the effectiveness of internal controls, and the factors affecting internal control deficiencies may vary. Future internal control research can be further expanded in this perspective.

In addition, from the above review, the research on internal control of enterprises can be described as internal and external integration, many aspects are obtained, and effective research results are obtained. With the deepening of research, research horizons will continue to be developed. For example, local government officials are an important factor affecting local economic and social development and whether their personal characteristics will affect the internal control of enterprises? These are still needed to be studied.

\section{Acknowledgements}

When the paper is completed, I would like to thank my tutor for his careful guidance. In the process of writing a thesis, I encountered a lot of questions and questions, and the teacher will answer me seriously. Whether it is the direction and topic at the beginning of the paper, or the structure and framework of the paper, the instructors have given guidance and advice on the revision of the paper from the overall layout to the format. His profound academic literacy has helped me a lot in my thesis.

\section{Conflicts of Interest}

The author declares no conflicts of interest regarding the publication of this paper.

\section{References}

[1] Ji, D., Wang, Y. and Chen, F. (2014) Does Ceo Incentives Improve the Effectiveness of Internal Control?-Evidence from State-Owned Listed Companies. Accounting Research, No. 6, 67-69.

[2] Zhao, Y.X. and Wu, W.R. (2014) Research on the Influence of External Regulation of Enterprises on Internal Control Effectiveness-Evidence from Chinese Listed 
Companies. China Soft Science, No. 4, 126-130.

[3] Yu, H.Z. and Wu, Y.L. (2015) Equity Incentives and Internal Control Effectiveness in the Contract Period-Based on the Perspective of Stock Options and Restricted Stocks. Audit Research, No. 5, 57-60.

[4] Lü, J.S. and Zhao, Y.M. (2016) Research on the Influence of Board Characteristics on Internal Control Failure-Based on Data Analysis of Chinese Listed Companies. China Soft Science, No. 5, 93-97.

[5] Chi, G.H., Yang, J. and Zou, W. (2014) Research on the Influence of Executive Background Characteristics on Internal Control Quality-Evidence from Chinese Share Listed Companies. Accounting Research, No. 11, 68-70.

[6] Chen, H.W. and Zhou, Z.S. (2014) Internal Control Quality and Corporate Debt Financing Costs. Nankai Management Review, No. 3, 104-106.

[7] Zhai, D., Fu, P. and Yang, D. (2015) Media Type, Media Concern and Internal Control Quality of Listed Companies. Accounting Research, No. 4, 79-82.

[8] Yin, M.Q., Zhao, G. and Zhang, J.D. (2015) The Impact of Monetary Policy on the Quality of Internal Control-An Empirical Study Based on the Shanghai Stock Market. China Soft Science, No. 8, 107-110.

[9] Wang, Y.L. and Wang, A.Q. (2014) Internal Control Defect Disclosure, Internal Control Audit and Debt Capital Cost-Evidence from Shanghai A-Share Listed Companies. China Soft Science, No. 2, 151-155.

[10] Shao, C.Y., Wang, P.F. and Zhou, Y.B. (2015) Research on the Impact of Ultimate Controlling Shareholders on Internal Control Defects-Based on Empirical Data of Chinese Manufacturing Listed Companies from 2009 to 2013. Audit Research, No. 4, 82-87.

[11] Zhang, C. and Liu, X. (2015) Information Disclosure of Internal Control Defects and Enterprise Investment Efficiency-Based on Empirical Research of Chinese Listed Companies. Nankai Management Review, No. 5, 136-139.

[12] Shang, Z.Y. and Qiu, J. (2016) Independent Directors Resign, Major Internal Control Defects and Non-Standard Audit Opinions-Evidence from Chinese Listed Companies. Audit Research, No. 1, 94-100.

[13] Fang, H.X. and Chen, Z.H. (2015) Can High-Quality Internal Control Effectively Deal with Trait Risks and Systemic Risks?. Accounting Research, No. 4, 72-76.

[14] Ye, K.T., Cao, F. and Wang, H.C. (2015) Can Internal Control Information Disclosure Reduce the Risk of Stock Price Collapse? Financial Research, No. 2, 1002-7246.

[15] Xu, Z.H. and Zhou, Z.F. (2016) Internal Control, Over-Investment and Corporate Credit Risk-Evidence from Shanghai A-Share Listed Companies. Chinese Management Science, No. 9, 25-28.

[16] Wang, Y.H. and Shi, Q.M. (2016) Does the Internal Control Norm System Have Any Inhibitory Effect on the Company's Risk Tolerance?-Analysis of the Risk Consequences of the Chinese Version of the Sarbanes-Oxley Act. Audit Research, No. 3, 92-95.

[17] Tang, D.P. (2014) International Reference and Institutional Innovation of Public Sector Internal Control. Financial Research, No. 5, 71-73.

[18] Chen, Y.L., Zhang, L. and Meng, Y. (2016) Asset Management Model of Public Institutions Based on Internal Control. Financial Research, No. 5, 40-43.

[19] Tang, D.P., Ji, J.H. and Zhi, B. (2015) Internal Control Evaluation of Administrative Institutions: Model Selection and Index Construction. Accounting Research, No. 1, 68-71. 
[20] Tang, D.P. and Li, X.Y. (2015) The Path of National Audit Promoting and Improving the Internal Control of Administrative Institutions. Audit Research, No. 2, 56-58. 